with an intensification of the subtropical high pressure over the North Atlantic gyre (Lohmann, 2003; Vellinga and Wood, 2002; Vellinga and $\mathrm{Wu}, 2004)$. These conditions result in a precipitation deficit in the tropical/subtropical North Atlantic, coupled with a freshening of the tropical/subtropical South Atlantic. Covariation between shifts in the Atlantic ITCZ, as inferred from the Cariaco Basin Fe record, and changes in North Atlantic gyre salinity suggest that a similar oscillation may have operated in the Atlantic during MIS 3 on millennial timescales, resulting in elevated North Atlantic gyre SSS during stadials.

Based on these results, it appears that surface waters in the Caribbean and the subtropical gyre became exceptionally salty during glacial/stadial intervals over the last $136 \mathrm{kyr}$. Correlations between tropi$\mathrm{cal} /$ subtropical SSS change, inferred AMOC variability and meridional shifts in the ITCZ suggest that changes in ocean circulation and the tropical hydrological cycle combined to alter the glacial/stadial Atlantic salinity budget. Results indicate that as the ITCZ migrated southward during stadials, water vapor supply to the North Atlantic decreased and/or water vapor removal increased (Xie et al., 2007). This lead to the accumulation of salt in the tropical/subtropical North Atlantic, which was not advected out of the basin due to reduced AMOC. Therefore, the hydrological cycle may act as a negative feedback during weak phases of AMOC, increasing North Atlantic surface water density and preconditioning the system for a return to an interstadial mode of strong AMOC. More intriguing is the possibility that these elevated stadial gyre salinities played a critical role in maintaining North Atlantic SSS high enough to allow for the rapid resumption of North AMOC, in spite of increased freshwater input associated with interstadial warming events.

\section{Note}

All data are archived at the NOAA Paleoclimatology Database: www.ncdc.noaa.gov/paleo/

\section{Acknowledgements}

We thank the Ocean Drilling Program (ODP) for core samples. Funding for this research was provided by a JOI-ODP Schlanger Ocean Drilling
Fellowship to M. Schmidt and by U.S. NSF grant 0327060 to H. Spero. Laboratory assistance from D. Pak and mass spectrometer operation by G. Paradis and D. Winter were critical to the success of this study. Elemental analyses were conducted in D. Lea's lab at UC Santa Barbara.

\section{References}

McManus, J.F., Francois, R., Gherardi, J.-M., Keigwin, L.D. and BrownLeger, S., 2004: Collapse and rapid resumption of Atlantic meridional circulation linked to deglacial climate changes, Nature, 428: 834-837.

Peterson, L.C., Haug, G.H., Hughen, K.A. and Rohl, U., 2000: Rapid changes in the hydrologic cycle of the Tropical Atlantic during the last Glacial, Science, 290: 1947-1951.

Schmidt, M.W., Spero, H.J. and Lea, D.W., 2004: Links between salinity variation in the Caribbean and North Atlantic thermohaline circulation, Nature, 428: 160-163.

Schmidt, M.W., Vautravers, M.J. and Spero, H.J., 2006a: Rapid subtropical North Atlantic salinity oscillations across Dansgaard-Oeschger cycles, Nature, 443 (doi: 10.10381/nature05121): 561-564.

Schmidt, M.W., Vautravers, M.J. and Spero, H.J., 2006b: Western Caribbean sea surface temperatures during the Late Quaternary, Geochemistry Geophysics Geosystems, 7(2): doi: 10.1029/2005GC000957.

For full references please consult:

www.pages-igbp.org/products/newsletter/ref2008_1.htm

\title{
The bipolar seesaw on the Iberian margin stretching over the past 420,000 years
}

\section{Joan O. Grimalt ${ }^{1}$ and Belen Martrat ${ }^{2}$ \\ 'Department of Environmental Chemistry, Institute of Chemical and Environmental Research, Barcelona, Spain; jgoqam@cid.csic.es \\ ¿2spanish National Research Council, Barcelona}

Continuous cores of ancient ice recovered from Greenland and Antarctica contain unique records of changes related to the air temperature. While several ice age cycles have been recovered for Antarctica (Jouzel et al., 2007), only one climate cycle (i.e., interglacial followed by a glacial period) has been recovered from Greenland (NGRIP members, 2004). This fact presents a challenge if we are to estimate the climate variability at European latitudes, as past temperatures in Antarctica rose and fell gradually, whereas sudden transitions occurred in the Greenland record. A possible explanation for this interhemispheric climate pattern is thresholds and nonlinear hysteresis behavior (i.e., the state of the dynamic system depends on its history) in the climate system (Stocker and Wright, 1991).

The Iberian Margin is a real laboratory for describing hydrological conditions from surface and deepwater masses, from the northern Atlantic and Antarctic regions, respectively. At this location, the surface temperature record very closely resembled the temperature record over Greenland, whereas the deep-temperature estimates were in line with Antarctica, hence provid- ing the opportunity for further testing on the seesaw connection between hemispheres (Blunier and Brook, 2001; Shackleton, 2001; Stocker and Johnsen, 2003).

To contribute to this knowledge of the northern hemisphere climate, a recent study (Martrat et al., 2007) worked on new Iberian sites (Marion Dufresne sediment cores MD01-2443 and MD01-2444). Two questions were posed: Firstly, what were interglacial-to-glacial cycles like, prior to the last one? Secondly, which climatic processes were providing the link between Mediterranean centennial variability and the polar regions? It must be emphasized that conclusions were mainly based on the temporal changes and relative phasing between different indicators measured along each of the two cores. The conclusions were consequently irrespective of the absolute timescale chosen.

In this study at the Iberian Margin, Dansgaard-Oeschger saw-tooth-type variability and associated interhemispheric linkage were both common robust features over the past four climate cycles (420 kyr). Iberian sea surface temperature (SST) variability and stable isotope ratios in ice-water molecules from Greenland had correlation coefficients of up to 0.92 (Martrat et al., 2007). Correlation coefficients for Iberian deep-ocean temperature variability and stable isotope ratios of Antarctic ice-water molecules were similarly high (Martrat et al., 2007). None of the climate cycles studied was an exact reproduction of another (Figs. 1-4). This fact was not surprising, as the governing factors of ice-age dynamics were never identical in the past. One point of interest-both in variable glacials and in the warm, relatively stable preceding periods - was that the SST variability increased while the Pleistocene progressed to the present (annual mean $\mathrm{U}^{\mathrm{k}^{\prime}}{ }_{37}$-SST; Figs. 1-4A). Warming stages of limited duration were designated as Iberian Margin Interstadials (IMI) and short-term cooling stages as Iberian Margin Stadials (IMS), with the number of the climate cycle to which they belong always shown immediately before.

Glacial periods were recognized by frequent incursions of extremely cold surface waters traced by the distribution of coccolith-synthesized alkenones, very likely associated with generations of icebergs in the northern Atlantic (increased per- 
centages of $C_{37: 4}$; Figs. 1-4B, inverted axis). Eighteen events occurred during the first climate cycle (1IMI and 1IMS events 1-18), nine in the second (2IMI and 2IMS events 1-9), seven oscillations during the third (3IMI and 3IMS events 1-7) and six over the fourth (4IMI and 4IMS events 1-6).

However, as previously observed (Martrat et al., 2004), the magnitude of drops in SST was often more pronounced during interglacials. At least four intense events of this nature interrupted the interglacial of the last climate period (1IMS-21, 1IMS-22, 1IMS-24 and 1IMS-25), three severe oscillations punctuated the second one (2IMS-11, 2IMS-12, 2IMS-13), just two during the third (3IMS-9, 3IMS-10) and none over the fourth climate cycle, until sudden entry into a glacial in a single event (4IMS-7).
This climate variability is specifically relevant at human scale as it encompasses changes in timescales short enough to be noticed in the time frame of a regular human life. The intensity of the changes was in some cases similar to the glacial to interglacial transitions at the onset of every climate cycle and the changes lasted long enough (from 100 to $7400 \mathrm{yr}$ ) to constitute long stages from a human perspective.

Different hydrological indicators were considered for the purposes of evaluating the causes of this abrupt climate variability. First, the benthic $\delta^{13} C_{c c}$ record (calcite $\delta^{13} \mathrm{C}$ ) which reflects the influence of deepwater masses from both hemispheres (north Atlantic deep water, NADW, 1.1\%; and Antarctic bottom water, AABW, 0.5\%o; Figs. 1-4C). Second, molecular fossil organic compounds originally synthesized by terrestrial flora, which, once accumulated on the sea floor, trace the deep ocean ventilation (decreased percentages of $\mathrm{C}_{26} \mathrm{OH}$ measure higher oxic transformation of these compounds and thus higher deep-ocean ventilation; Figs. 1-4D). Finally, the benthic $\delta^{18} \mathrm{C}_{\text {cc }}$ record (calcite $\delta^{18} \mathrm{O}$ ), a proxy for ice volume and deep-sea temperatures, is reminiscent of Antarctica gradual events (Figs. 1-4E).

Particularly for the Holocene, $1 \mathrm{IMI}-26$ and $4 \mathrm{IMI}-10$, decreases in the $\mathrm{C}_{26} \mathrm{OH}$ ratio and increases in benthic $\delta^{13} C_{c c}$ ratios marked the beginning of every climate cycle, characterized by a deep-sea floor ventilated with powerful arrival of north Atlantic Deepwater (NADW). Harsh drops in SST were preceded by steep decreases in

Figure 1 - 4: The lberian margin paleoarchive over first to fourth interglacial to glacial cycle. $\boldsymbol{A})$ Changes in SST; $\boldsymbol{B}) \%$ of heptatriatetraenone (C ${ }_{37: 4}$ to total alkenones, indicating arctic surface water at core location; $\boldsymbol{C}$ ) Benthic $\delta^{13} \mathrm{C}$ (three point running average) indicating influence of NADW ( 1\%) and AABW (less than 0.5\% . Arrows indicate increasing flows of NADW or AABW; D) Relative proportion of n-hexacosan-1-ol $\left(\mathrm{C}_{26} \mathrm{OH}\right)$ to the sum of n-hexacosan-1-ol $\left(\mathrm{C}_{26} \mathrm{OH}\right)$ plus $n$-nonacosane $\left(\mathrm{C}_{2}\right)$ providing an oxygenation marker of deep-sea floor (three-point running average); $E$ ) Benthic $\delta^{18} \mathrm{O}$ (three point average). Numbers over the SST record indicate Iberian Margin Interstadials (IMI), numbers within the blue filling indicate Iberian Margin Stadials (IMS), grey diamonds in First Glacial Cycle represent ${ }^{14} \mathrm{C}$ dates. Gray shaded bars indicate abrupt cooling episodes, yellow shaded bars indicate deglaciation periods. AABW = Antarctic Bottom Water, NADW = North Atlantic Bottom Water, LGM = Last Glacial Maximum.
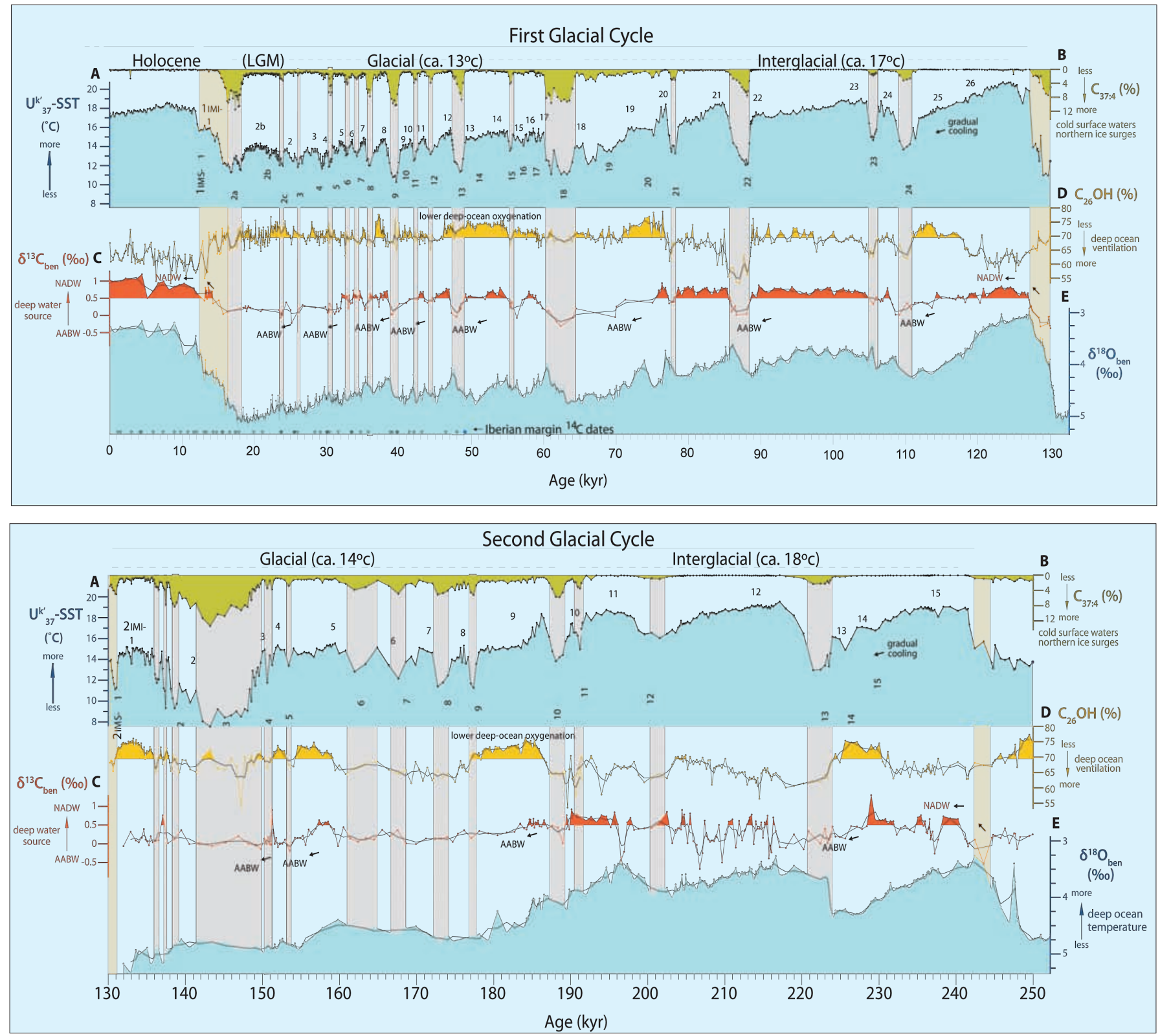
both $\mathrm{C}_{26} \mathrm{OH}$ and benthic $\delta^{13} \mathrm{C}_{\mathrm{cc}}$ ratios, when the predominance changed from NADW to southern (Antarctic Bottom Water, AABW), a few centuries before the subsequent northern ice surges (Martrat et al., 2007; Figs. 1-4).

Abrupt changes are often defined by observing the effect of climate conditions on the ocean surface and continental land masses. However, this study showed that they occurred simultaneously with reorganization of the deepwater masses in the northern Atlantic Ocean and the arrival of AABW at latitudes such as those of the Iberian peninsula. The important lesson is that due to the non-linear behavior of the ocean-atmosphere-sea ice system in the northern hemisphere, apparent gradual external triggers or slow changes in the deep ocean preceed rapid climate oscillations in the Mediterranean region at surface level. The implications are certainly challenging:
A complete bifurcation in the climate conditions of this region will only be preceded by subtle and hardly identifiable changes.

This climate variability responds to the natural climate evolution of the planet. It is not related to human influence but has exerted a huge impact on tree populations around the Mediterranean by exceeding their tolerance limit, leading to population crashes and subsequent predominance of herbaceous, treeless vegetation (Tzedakis et al., 2004).

It has long been known that glacial and interglacial periods are modulated by orderly trends determined by the gradual variation of the Earth's orbital geometry. In contrast, millennial-scale abrupt climate change occurs when the climate system is forced to cross a threshold, triggering the transition into a new climate condition at a rate faster than the cause (Alley et al., 2003).

\section{Acknowledgements}

We thank the many people who have contributed to our work; particularly M. Hutterli, T. Stocker and L. de Abreu. We would like to pay a tribute to the late Professor Sir Nicholas J. Shackleton; his presence and his wisdom are greatly missed.

\section{References}

Blunier, T. and Brook, E.J., 2001: Timing of millennial-scale climate change in Antarctica and Greenland during the last glacial period, Science, 291: 109-112.

Martrat, B., Grimalt, J.0, Lopez-Martinez, C., Cacho, I., Sierro, F.J., Flores, J.A, Zahn, R., Canals, M., Curtis, J.H. and Hodell, D.A., 2004: Abrupt temperature changes in the western Mediterranean over the past 250,000 years, Science, 306: 1762-1765.

Martrat, B., Grimalt, J.0., Shackleton, N.J., de Abreu, L., Hutterli, M.A. and Stocker, T.F., 2007: Four climate cycles of recurring deep and surface water destabilizations on the Iberian Margin, Science, 317 502-507, published online 14 June 2007.

Shackleton, N.J., 2001: Climate change across the hemispheres, Science, 291: 58-59

Stocker, T.F. and Wright, D.G., 1991: Rapid transitions of the ocean's deep circulation induced by changes in surface water fluxes, Nature, 351: 729-732.

For full references please consult:

www.pages-igbp.org/products/newsletter/ref2007_3.htm |
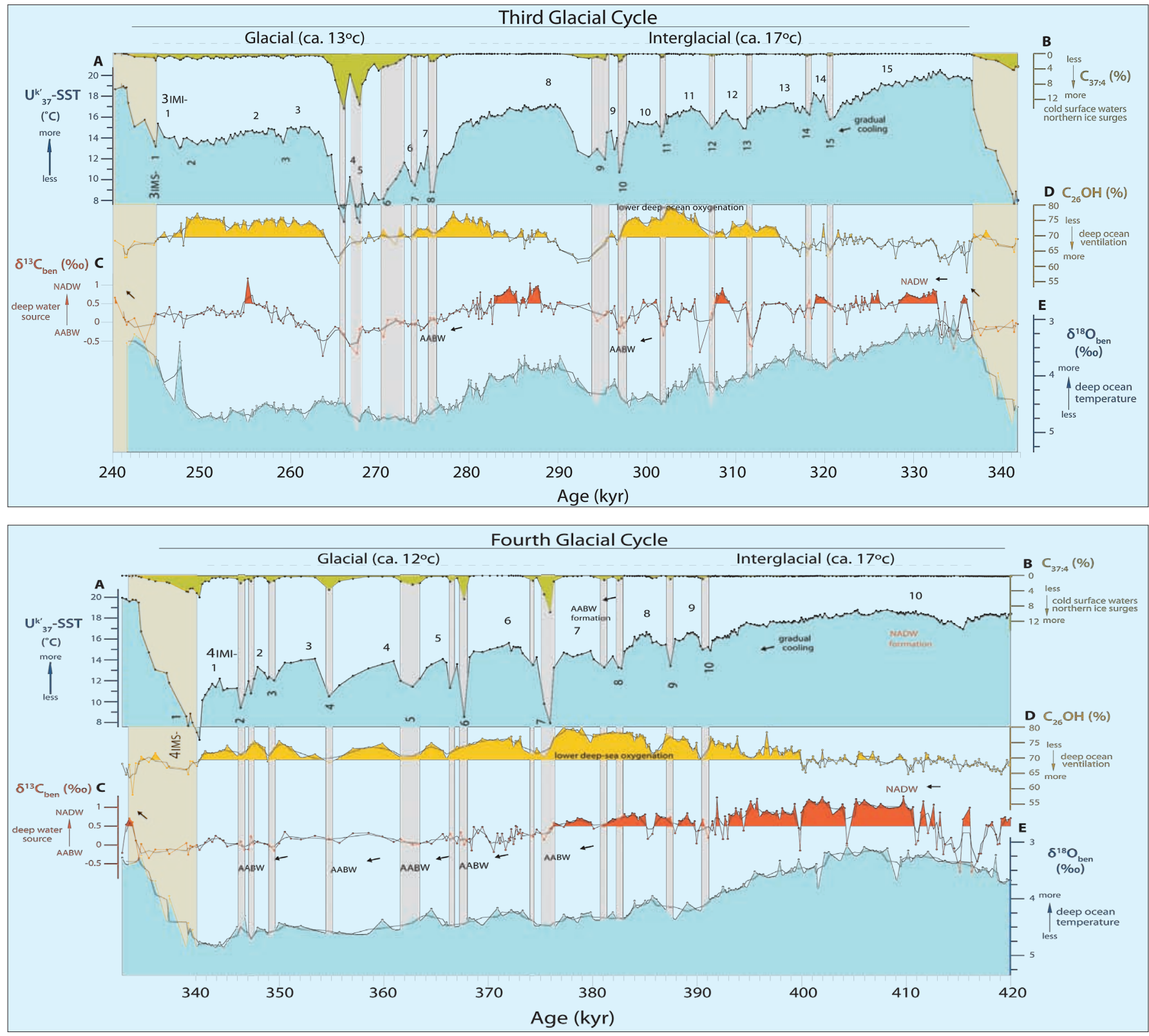